Migliozzi, S; Paulillo, A; Chirone, R; Salatino, P; Solimene, R; (2017) Hydrodynamics of compartmented fluidized beds under uneven fluidization conditions. Powder Technology, 316 pp. 476491. 10.1016/j.powtec.2016.12.052. Downloaded from UCL Discovery:

http://discovery.ucl.ac.uk/10053452/.

\title{
ARTICLE
}

\section{Hydrodynamics of compartmented fluidized beds under uneven fluidization conditions}

\author{
Simona Migliozzi ${ }^{1}$, Andrea Paulillo ${ }^{1}$, Riccardo Chirone ${ }^{2}$, Piero Salatino ${ }^{1}$, Roberto Solimene, ${ }^{2 *}$ \\ ${ }^{1}$ Dipartimento di Ingegneria Chimica, dei Materiali e della Produzione Industriale, \\ Università degli Studi di Napoli Federico II, Piazzale Vincenzo Tecchio 80, 80125 Napoli (Italy). \\ ${ }^{2}$ Istituto di Ricerche sulla Combustione, Consiglio Nazionale delle Ricerche, \\ Piazzale Vincenzo Tecchio 80, 80125 Napoli (Italy).
}

\begin{abstract}
Fluidized beds may be conveniently applied to demanding thermal and thermochemical processes thanks to their inherently good thermal performances: bed-to-surface heat transfer coefficients, effective thermal diffusivities. Collection and thermal storage of solar radiation in Concentrated Solar Power (CSP) systems is one challenging example of this application. Thermal properties may be further enhanced by non-conventional design and operation of fluidized beds based on uneven or unsteady (pulsed) fluidization. A novel concept of solar receiver for CHP (combined heat and power) generation consisting of a compartmented dense gas fluidized bed has been proposed to effectively accomplish collection of incident solar radiation, heat transfer to the working fluid of the thermodynamic cycle and thermal energy storage. This application, like others of the same kind, poses the objective of achieving controlled compartmentation of a large scale fluidized bed by selectively promoting fluidization in some regions while keeping others in a fixed state. This task may be accomplished by means of a compartmented windbox, without physical partitioning or internals immersed in the bed. This study addresses this problem by investigating the hydrodynamics of a near-2D dense gas-fluidized bed operated at ambient conditions and equipped with a compartmented fluidizing gas distributor. The hydrodynamics was characterized by pressure measurement at different locations in the bed to mark the onset of local fluidization and to map the extension and location of fluidized and de-fluidized regions in the bed for different choices of operating conditions. An important follow-up of the study is the analysis of the dynamics of the bubble and emulsion phase in an unevenly fluidized bed. Dynamical patterns of bubble and emulsion phases have been scrutinized by analysis of space- and time-resolved void fraction profiles obtained by electrical capacitance measurements.
\end{abstract}

Altogether results indicate that a perfectly compartmented fluidized bed cannot be obtained simply using a compartmented windbox. However a proper choice of fluidizing gas partitioning between the compartments enables good control of the local fluidization conditions, of gas cross-flow between the compartments, of large-scale solids circulation.

Keywords: uneven fluidization, compartmented fluidized bed, electrical capacitance, concentrated solar power, thermal energy storage. 


\section{Introduction}

The development of solid particle receivers in Concentrated Solar Power (CSP) applications is gaining much interest [1-4]. Among particle receivers, dense gas-solid fluidized suspensions have been recently proposed as heat transfer fluid (HTF) and thermal energy storage media [3-8] thanks to their excellent thermal properties, namely bed-to-wall heat transfer coefficient (several hundreds of $\left.\mathrm{W} / \mathrm{m}^{2} \mathrm{~K}\right)$ and effective thermal diffusivities $\left(0.001-0.1 \mathrm{~m}^{2} / \mathrm{s}\right)$ associated with convective transfer due to bubble-induced and gross bed solids circulation [9-11]. Both these features may be optimized by proper selection of fluidized solids type and size and fluidization regime. Non-conventional design and operation of fluidized beds based on uneven or unsteady (pulsed) fluidization may further enhance their thermal performances for CSP and thermal energy storage applications [8]. The use of fluidized solids as alternative to other storage/exchange media, like molten salts, entails the possibility to overcome issues associated with the use of corrosive or environmentally unfriendly fluids and to operate the receiver at much higher temperature under direct irradiation of solid particles [12-15]. Furthermore, the potential of solar-irradiated gas-solid fluidized beds is related to the possibility to perform solar-driven thermo-chemical processes [16-17] for production of solar fuels and chemicals [18-23].

Dense gas-solid fluidized beds have the potential to effectively accomplish three basic complementary tasks: a) collection of incident solar radiation; b) transfer of the incident power to heat exchange surfaces and henceforth to high-efficiency power cycles; c) thermal energy storage, aimed at equalizing the inherent time-variability of the incident radiation for stationary combined heat and power (CHP) generation. All these features have been exploited in a novel concept of solar receiver for $\mathrm{CHP}$ generation with inherent thermal energy storage. The concept is based on a novel design of the solar collector, based on a compartmented dense gas fluidized bed optimized so as to accomplish the three complementary tasks [7]. Application of this concept poses a challenging task: how can compartmented fluidization of a large scale bed be achieved? By compartmented fluidization we mean the ability to achieve controlled fluidization of selected sections of a large scale bed while others are kept in the fixed or in a different fluidized state. To preserve the very favourable thermal and flow properties of the bed, this objective must be pursued without physical confinement of the bed or use of internals, but just by partitioning of the fluidizing gas to a compartmented gas distributor.

The hydrodynamics of a near-2D dense gas-fluidized bed operated at ambient conditions and equipped with a compartmented gas distributor will hereby be analysed. Bed hydrodynamics was characterized by pressure measurements at multiple locations in the bed to mark the onset of local fluidization. Pressure maps are worked out to assess the location and extension of fluidized and defluidized regions in the bed, under a range of operating conditions. Dynamical patterns of the bubble and of the emulsion phases are further investigated by analysis of space- and time-resolved void fraction profiles obtained by electrical capacitance measurements.

\section{Experimental}

\subsection{Experimental Apparatus and Materials}

Figure 1 shows the picture and the schematic representation of the experimental apparatus with its ancillary equipment. The experimental apparatus consists of a near-2D fluidized bed (2850x1860x200mm) equipped with an array of pressure taps at different locations in the bed. The fluidized bed can be considered as "nearly two-dimensional" because it is characterized by a thickness much smaller than the other dimensions, but at the same time large enough to prevent extensive wall effects for bubbles smaller than $120 \mathrm{~mm}$. Accordingly, the test facility can be used to investigate bed hydrodynamical patterns along the width and the height of the bed as they would develop in full-scale 3D compartmented fluidized beds.

The fluidization column, whose size is $3000 \times 2000 \times 200 \mathrm{~mm}$, is made of a frame of steel profiles (UPN $200)$, on which two Plexiglas sheets $3000 \times 2000 \times 20 \mathrm{~mm}$ are rigidly connected. The fluidized bed is located on a movable frame of steel profiles (UPN 160) and can be tilted up to a maximum angle of $90^{\circ}$ with respect to the vertical, to make maintenance and insertion of internals easier. 10 holes were drilled on the steel frame of the fluidization column (three each on left and right sides and on the top, 
and one on the bottom) used as diagnostic taps and inlet and outlet ports. Threaded pipes, 3" O.D. on the upper side, 2" O.D. on the other sides were welded at hole locations. These ports were necessary for air distribution system (left and right), pressure monitoring system (left, right and top), capacitance probes and for discharge of bed material (lower side).

The bed was equipped with two spargers acting as gas distributors. They consisted of 1.5" perforated pipes, respectively 372 and $1488 \mathrm{~mm}$ long, assembled with a bayonet-type connection. The holes (ID $2 \mathrm{~mm}$ ) of the distributor were drilled $31 \mathrm{~mm}$ apart along a single row and were directed downwards. The holes were covered by metallic mesh to prevent dumping/weeping of bed solids in the spargers. The distributors were immersed in the bed horizontally at the distance of $100 \mathrm{~mm}$ above the base of the frame. The spargers were intentionally of different length so that it was possible to establish uneven fluidization of the bed with asymmetric patterns. Accordingly, we will denote the spargers, and the corresponding sections of the fluidized bed, as $L$ (long, the $1488 \mathrm{~mm}$ long sparger), and $S$ (short, the $372 \mathrm{~mm}$ ). 


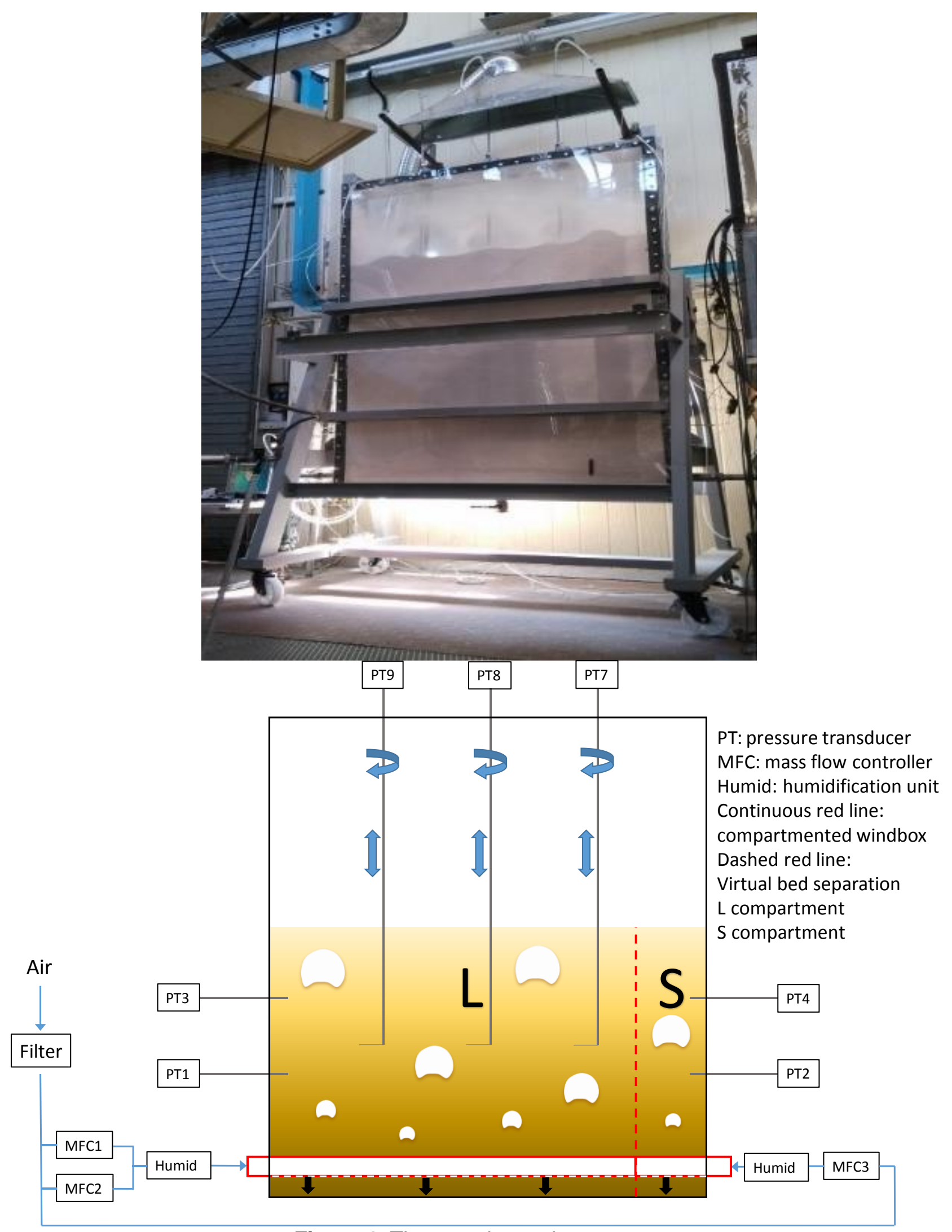

Figure 1. The experimental apparatus. 
Positions in the bed are identified in a coordinate system $(O, x, h)$ whose origin $O$ is located on the side wall of the $L$ compartment just above the $L$ sparger. The coordinate $x$ represents the distance from the side wall of the $L$ compartment while the coordinate $h$ represents the distance from the upper surface of the distributor. Correspondingly, and considering the position of the spargers, two adjacent sections of the bed are identified, namely $L$, extending over $0<x<1480 \mathrm{~mm}$, and $S$ extending over $1480<x<1860 \mathrm{~mm}$.

The fluidizing gas was technical-grade air fed by a system consisting of a filter, a set of mass flow rate controllers (BRONKHORST EL-FLOW model F203-AV, F.S. 98 and $45 \mathrm{Nm}^{3} / \mathrm{h}$ and precision \pm $0.1 \mathrm{Nm} 3 / \mathrm{h}$ ) and a humidification system. The filter, located upstream of the controllers, removed any residual oil and dust coming from the compressed air supply line. Air flow rate was controlled by a personal computer, interfaced to the instrument via a serial RS232 connection. The humidification system was required to prevent electrostatic charging due to friction of bed material with the Plexiglas walls, and consisted of a bubble column located downstream of each controller. The humidification system can be also by-passed in order to allow the alternation of dry and humid air flow rate, for better control of bed material moisture.

The bed material was fine silica sand with a mean Sauter diameter of $145 \mu \mathrm{m}$. Its properties are reported in Table 1. Fine bed solids were chosen for CSP applications in order to obtain large heat transfer coefficient and effective thermal diffusivity even at small fluidization velocities.

Table 1. Physical properties and incipient fluidization velocity of bed material.

\begin{tabular}{|c|c|}
\hline Material & Quartz \\
\hline Density, $\mathrm{kg} / \mathrm{m}^{3}$ & 2560 \\
\hline Size range, $\square \mathrm{m}$ & $63-317$ \\
\hline Sauter mean diameter, $\square \mathrm{m}$ & 145 \\
\hline $\begin{array}{l}\text { Powder Group, } \\
\text { according to Geldart classification }\end{array}$ & B \\
\hline Ar, - & 280 \\
\hline \multicolumn{2}{|l|}{ Incipient fluidization velocity, $\mathrm{m} / \mathrm{s}$} \\
\hline Experimental & 0.018 \\
\hline Theoretical & 0.018 \\
\hline
\end{tabular}

\subsection{Diagnostics}

A static gas pressure measurement system based on piezoresistive pressure transducers (Keller PR-23X and PR-23Y; full scale: 0.2 and 0.5 bar; accuracy: $0.15 \% \mathrm{FS}$ ) was used to map fluidization conditions inside the fluidized bed. The system consists of three movable probes which can be immersed directly in the bulk of the bed at different levels above the distributor. Additionally, four fixed probes are located at different locations at the lateral walls. The three movable probes are vertically inserted inside the bed from the top side of the apparatus. The movable pressure probe consists of a $12 \mathrm{~mm}$ O.D., $3 \mathrm{~m}$ long pipe connected to an L-shaped probe, $6 \mathrm{~mm}$ OD, 200x100mm vertical $x$ horizontal. The choice of using a smaller diameter for the final section of the probe was dictated by the need to reduce the intrusiveness of the probe near the measurement location. The geometry of the probe prevented pressure measurement from being affected by the dynamic component associated with gas flow. Moreover, thanks to the elbow shape of the final section of the probe, each probe could be used to perform measurements at multiple locations by simply rotating the probe around its axis. Accordingly, gas pressure could be measured at coordinates $x=350,450$, $550,800,900,1000,1250,1350,1450 \mathrm{~mm}$ (lying in the L compartment of the bed) and $x=1600 \mathrm{~mm}$ (lying in the S compartment) using three vertical probes only. In addition to the movable probes, four fixed probes were inserted horizontally within the bed by means of the four measurement taps 
located along the two side walls (Figure 1). The pressure taps PT1, PT2 are located at a height of $400 \mathrm{~mm}$ from the base of the frame of the fluidized bed, while PT3, PT4 are placed at a height of $850 \mathrm{~mm}$ and they are devoted to measure the gas static pressure near the bed walls.

The dynamical behavior of the fluidized bed under even and uneven fluidization conditions and at different vertical and horizontal positions was characterized by two needle-shaped custom-made capacitance probes produced by MTI Instrument Inc.. The capacitance sensor is guarded-type [25] with an OD $1.5 \mathrm{~mm}$ inner protruding electrode $7.5 \mathrm{~mm}$ long and an OD $6.25 \mathrm{~mm}$ outer electrode. The measurement volume of such sensors is a cylinder of volume $V_{C}=230 \mathrm{~mm}^{3}$ and surface $S_{C}=147 \mathrm{~mm}^{2}$, which corresponds to a minimum detectable bubble of equivalent diameter of about $8 \mathrm{~mm}$. The capacitance sensors were assembled at the tip of $10 \mathrm{~mm}$ OD brass tubes that were slided horizontally so as to locate the probe at the desired location in the bed. The probes are long and stiff enough to perform accurate measurements up to a maximum distance of $900 \mathrm{~mm}$ from the side wall. The probes were connected to an AccuMeasure 9000 amplifier, provided by MTI Instruments Inc.. The amplifier acts as a power supply and ground to the probes, and features also signal postprocessing, if required.

All analog signals from the diagnostic system were acquired by means of an analog-digital conversion unit (National Instruments) interfaced with a personal computer. All the analog signals were monitored and postprocessed in the LabView data acquisition/programming environment. Raw data were further postprocessed by customized routines developed in the Matlab environment.

\subsection{Experimental procedure and post-processing of the raw data}

The experimental campaign is focused on the characterization of the hydrodynamics of the fluidized bed under even and uneven fluidization conditions with the aim of verifying the effectiveness of compartmented fluidization of the bed. To this end, partitioning of the fluidizing gas to the $L$ and $S$ spargers was metered so as to operate one section (either $S$ or $L$ ) as the "active" section of the bed, which implies that locally $U>U_{m f}$, while the other section was in a "passive" state, that is $0 \leq U<$ $U_{m f}$. Sections $S$ and $\mathrm{L}$ could be interchanged in the role of "active" and "passive" sections, so that the influence of relative lateral size of the "active" and "passive" sections could be assessed.

The gas static pressure measurement system was used to monitor pressures and pressure gradients to obtain the fluidization maps of the fluidized bed. The electrical capacitance signals were worked out to characterize the dynamics of the bubble and emulsion phases under even and uneven fluidization conditions, with particular emphasis on the flow patterns establishing in the proximity of the virtual bed separation between $L$ and $S$ compartments. The experimental procedure consisted of the following phases: 1) air flow rates at both spargers were initially set at values corresponding to $5 U_{m f}$ for $15 \mathrm{~min}$; 2) air flow rates were eventually set at the desired values; 3 ) after the bed settled to steady state, static gas pressure and capacitance signals were acquired at the pre-set array of measurement locations in the bed. Data acquisition was repeated iterated over 2 minutes with a sampling rate of $1 \mathrm{kHz}$ and $10 \mathrm{kHz}$ for pressure and capacitance signals, respectively. The matrix of experimental conditions included multiple values of static bed level $(0.55,1 \mathrm{~m}, 1.39$ and $1.85 \mathrm{~m})$ and air flow rates at the spargers $\left(U_{S}\right.$ and $U_{L}$ ranging between 0 and $\left.4 U_{m f}\right)$.

Pressure signals have been post-processed to obtain time-averaged values at each point of the array, which were eventually worked out to obtain the map of the fluidized and defluidized regions of the bed for each set of operating conditions. The procedure is illustrated with the aid of Figure 2. Black points represent the location of the pressure taps. The analysis involves calculation of pressure gradients between adjacent taps located on the same vertical (same values of $\mathrm{x}$ ). A pressure gradient exceeding a threshold of $0.11 \mathrm{mbar} / \mathrm{mm}(90 \%$ of that corresponding to minimum fluidization condition) was assumed to mark the onset of local fluidization. Local values smaller than the reference threshold indicate that the bed is locally de-fluidized (red line in Figure 2), otherwise the bed is considered locally fluidized (green line). 2-D interpolation of pressure gradients was directed to draw the boundaries between fluidized and de-fluidized regions of the bed (blue line in Figure 2). 


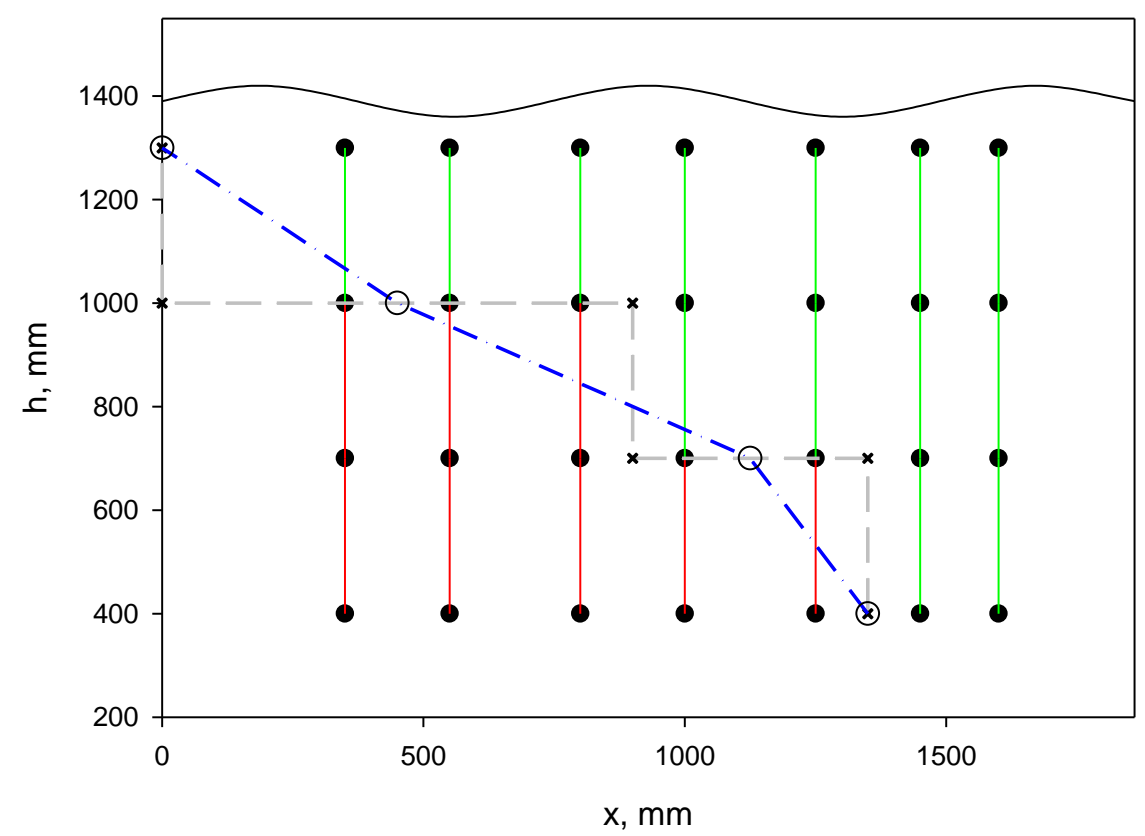

Figure 2. Contours of fluidized/defluidized regions of the bed from space- and time-resolved pressure measurements.

The time-resolved signal of capacitance probes is proportional to the dielectric constant of the medium and, in turn, is directly related to the temporal fluctuations of the void fraction or bed solids concentration of the fluidized bed according to a linear correlation with the output voltage signal $V$ of the probes, as suggested by Hage and Werther [25]:

$$
\varepsilon_{s}=\varepsilon_{s f b} \frac{V-V_{0}}{V_{f b}-V_{0}}
$$

where $\varepsilon_{s f b}$ is the fixed bed solid volume concentration, $V$ the signal voltage, $V_{0}$ the solids-free reference signal (only air) and $V_{f b}$ the fixed bed reference signal. Measurements of the time-resolved local void fraction $\left(1-\varepsilon_{s}\right)$ provide the basis for analyzing the dynamics of the bubble and emulsion phases, using the method developed by Molerus and Werther [26]. The procedure is based on the assumption that the signal is a convolution of a bubble-related component superimposed to the component associated with voidage fluctuations in the emulsion phase. Pulses associated with bubbles are of much larger amplitude than fluctuations of void fraction in the dense phase. The signal can be analyzed in terms of probability density functions (see Figure 3) which display a pronounced bimodal character. It is possible to set a threshold value, $V_{D}$, of the capacitance voltage signal for bubble phase detection. The mean bubble frequency $(k)$, the mean bubble rise velocity $\left(v_{b r}\right)$ and the mean bubble pierced length, $\left(l_{b}\right)$ have been computed from deconvolution of the bubble phase signal, whereas the mobility of dense phase was characterized by the standard deviation and power spectrum density of the time series of the decomposed bed solids volume fraction signal related to the dense phase. 


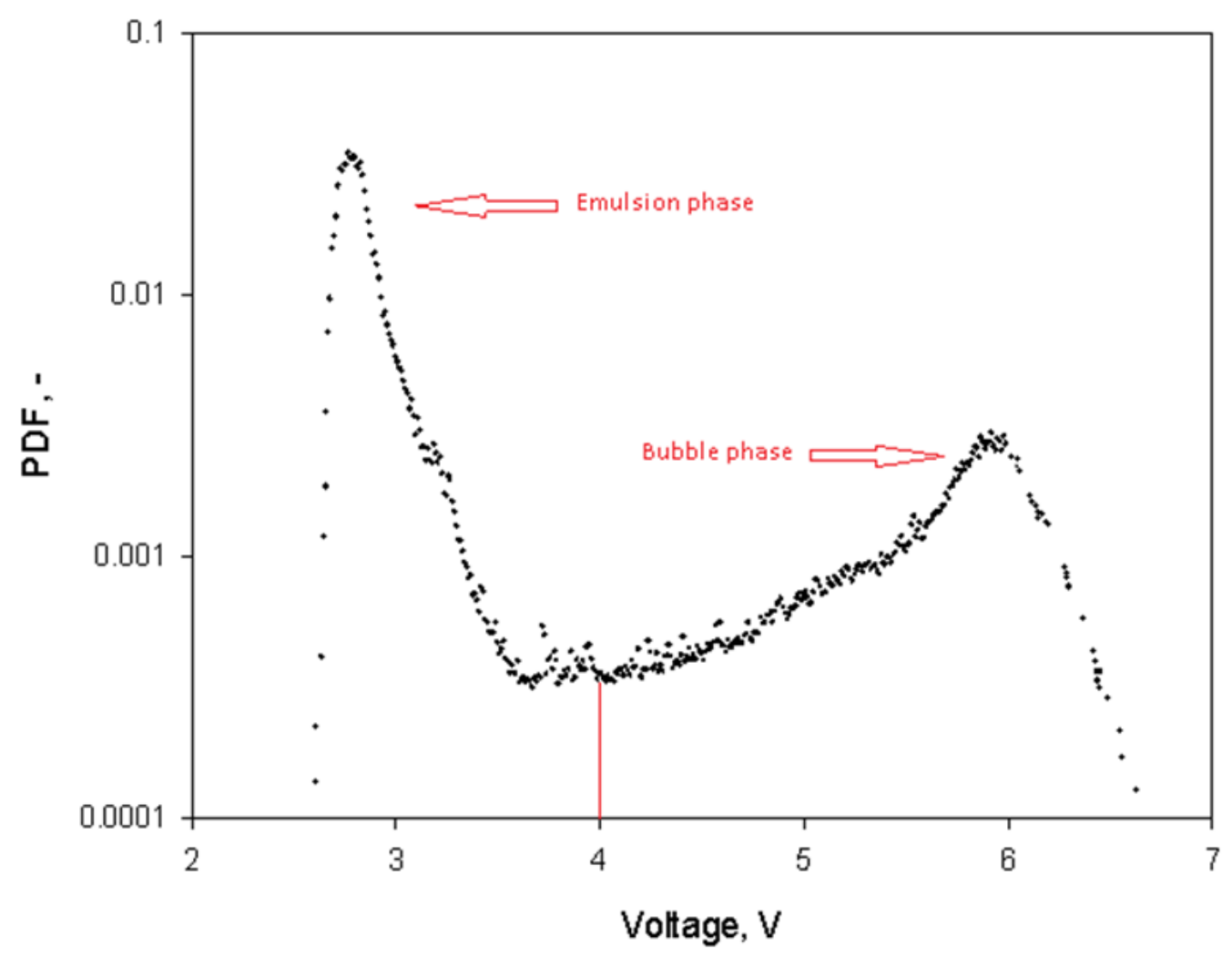

Figure 3. Probability density function (PDF) of a typical electrical capacitance signal. Bed height: $1 \mathrm{~m} ; U_{L}=0.66 U_{m f}, U_{S}=4 U_{m f}$, probe located at $\mathrm{x}=1697 \mathrm{~mm}, \mathrm{~h}=1000 \mathrm{~mm}$.

Capacitance signals were used to estimate the local solid dispersion coefficient using a kinetic theory approach for granular flows. The diffusion coefficient $D$ of solid particles can be estimated as the product of an average particle velocity $(\langle v\rangle)$ and a particle mean free path [27-28]:

$$
D=\frac{1}{3 \sqrt{8}} \frac{<v>d_{p}}{\epsilon_{s}}
$$

where $d_{p}$ is the particle diameter. The mean particle velocity has been calculated from the component of the capacitance signal associated with the dense phase as the product of standard deviation $\left(\sigma_{c v}\right)$ and the dominant frequency $(f)$ of dense phase concentration signal (amplitude and pulsation of the fluctuations) and the characteristic length of the measurement control volume:

$$
<v>=\frac{\sigma_{c v} V_{C} f}{s_{C}}
$$

\section{Results and discussion}

\subsection{Fluidization maps under uneven fluidization conditions}

Fluidization maps show the spatial distribution of fluidized and de-fluidized regions of the bed as partitioning of the fluidizing gas between the $S$ and $L$ sections was changed (one being active, the other passive) and as a function of the static bed height.

A first series of maps, reported in Figures 4-6, was obtained at fixed static bed height $(0.55,1$ and $1.85 \mathrm{~m}$, respectively), keeping constant the flow rate of fluidizing gas fed to the active section of the bed and varying the gas flow rate to the passive section. A second series of maps, reported in Figure 7, refers to experiments carried out with a fixed value of gas flow rates to the passive section (Left: $U_{L}=0.5 U_{m f}$ and $U_{S}=1.5,2.5,4 U_{m f}$; Right $U_{L}=0.33 U_{m f}$ and $U_{S}=1.5,2.5,4 U_{m f}$ ) for different values of the static bed height. The virtual bed separation into $L$ and $S$ compartments is marked in all the plots as a vertical dotted line. Separation boundaries between fluidized and de-fluidized regions are reported as dashed lines: the fluidized bed region lies to the right of the separation boundary when 
the $S$ compartment is "active" (hence $L$ is "passive"), it lies to the left when the $L$ is active and $S$ is passive.

The key to the interpretation of the fluidization maps will be illustrated by first considering the case of a fluidized bed of static bed height of $0.55 \mathrm{~mm}$ with the $S$ section set as the active section $\left(U_{S}=1.5 U_{m f}\right)$ as the gas flow rate at the $L$ sparger, hence $U_{L}$, is varied (Figure 4 right). Analysis of the plots suggests that the bed is only partially fluidized when $U_{L}=0$ : extended defluidized areas are observed also in the upper part of the S-compartment due to crossflow of the fluidizing gas from the active $S$ to the passive $L$ compartments. The bed is effectively compartmented when $0.33 U_{m f}<U_{L}<0.5 U_{m f}$ : the $S$ compartment is effectively fluidized, whereas the $L$ compartment stays in the fixed bed state. When $U_{L}>0.66 U_{m f}$, the whole bed is in the fluidized state. Results like those presented in Figure 4-right suggest how the bed should be operated to achieve effective compartmented fluidization of the bed by appropriate partitioning of the fluidizing gas between the two sections of the distributor. As the flow rate of fluidizing gas in the $S$ compartment is increased $\left(U_{S}=2.5\right.$ and $\left.4 U_{m f}\right)$, compartmentation is effectively observed with smaller flow rates in the passive L section: $U_{L}<0.5 U_{m f}$. 

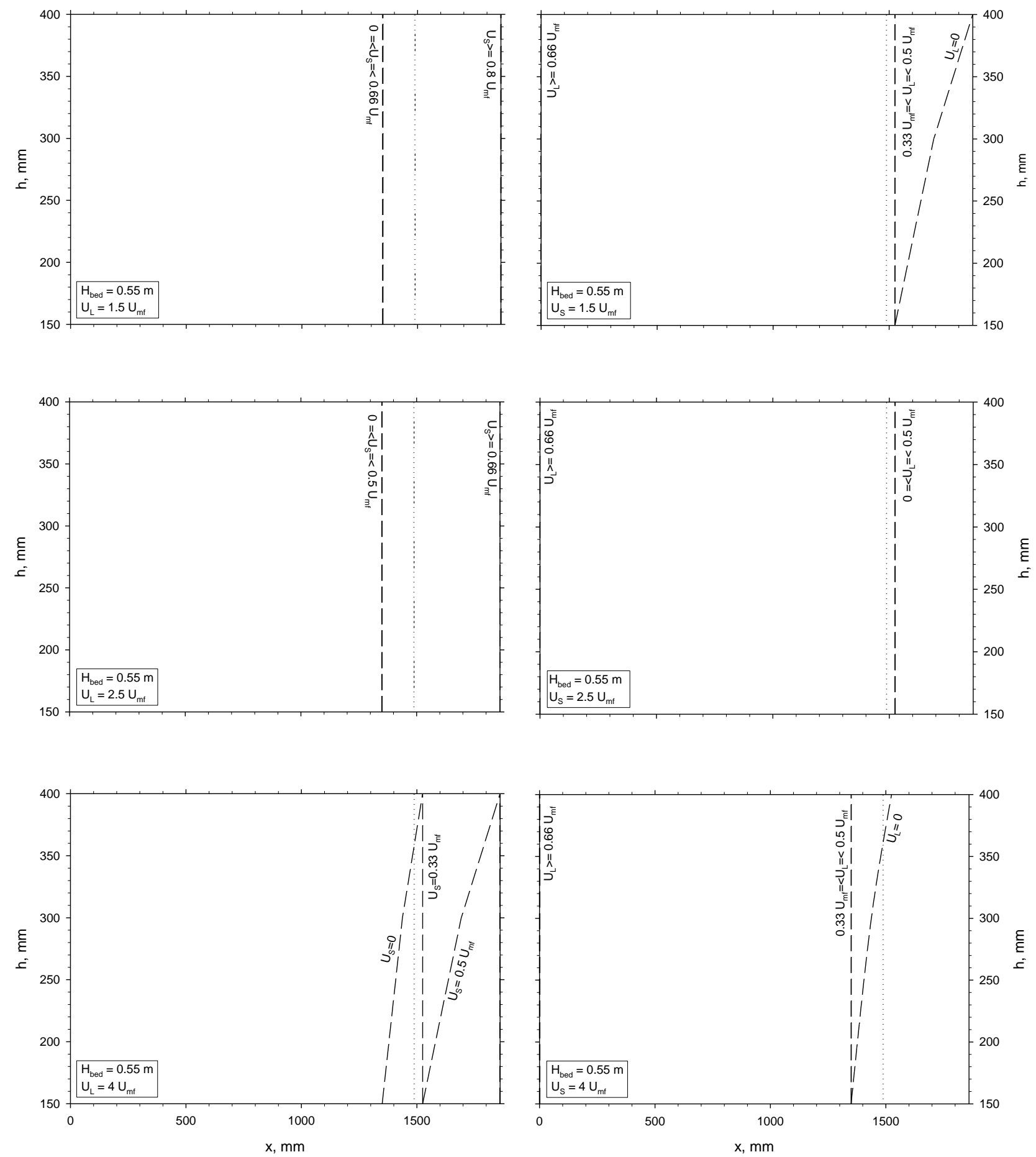

Figure 4. Fluidization maps for static bed height of $0.55 \mathrm{~m}$; (left) active section: L, (right) active section: $\mathrm{S}$. 
Similar findings refer the case when the $\mathrm{L}$ is the active compartment $\left(U_{L}>U_{m f}\right)$. Effective compartmentation is observed for $U_{L}=1.5,2.5$ and $4 U_{m f}$ provided that the gas flow rate in the passive $S$ compartment is set at $U_{S}<0.66,0.5,0.33 U_{m f}$, respectively.

Analysis of Figure 5 suggests that bed compartmentation is less effective when the static bed height is increased. As the static bed height is set at $1 \mathrm{~m}$ and the $\mathrm{L}$ compartment is active, the fluidized region extends also to large part of the passive $S$ compartment even when $U_{S}=0$. The extension of the fluidized region increases even further as the fluidization velocity of the $L$ compartment is increased. This pattern is obviously related to gas crossflow from the active $L$ zone to the non active $S$ zone, which is emphasized by bed depth [29]. The scenario is even more complex when $S$ is the active compartment. At $U_{S}=1.5 U_{m f}$, the $S$ compartment is largely de-fluidized when $U_{L}=0$. Compartmented fluidization is effectively established when $U_{L}=0.33 U_{m f}$, whereas for $U_{m f}>U_{L}>0.33 U_{m f}$, an increasingly large fraction of the passive $\mathrm{L}$ compartment is fluidized. For $U_{S}=2.5$ and $4 U_{m f}$, effective compartmentation is already set at $U_{L}<0.33 U_{m f}$. Similar results can be observed for even larger static bed heights, as shown in Figure 6. 

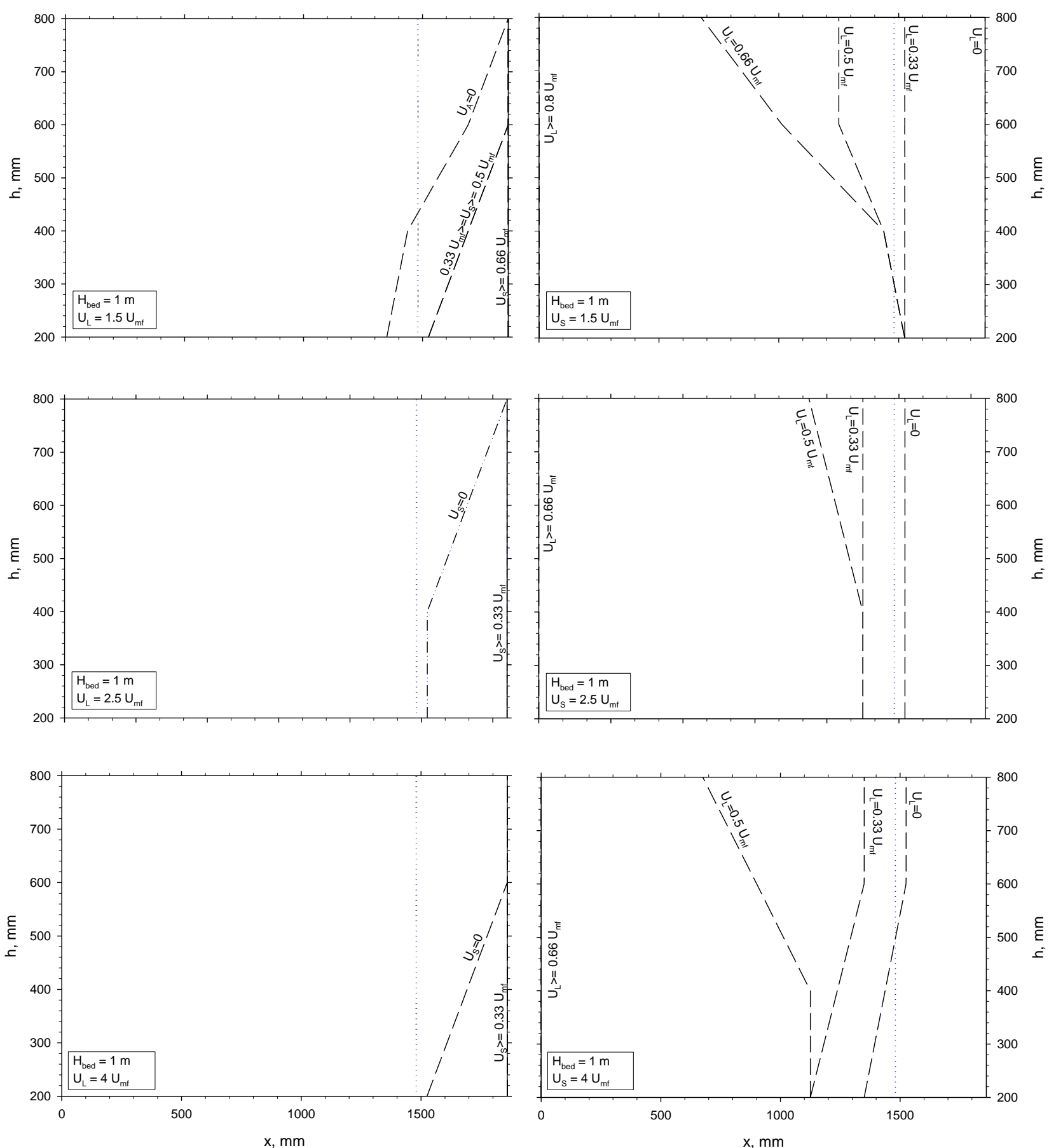

Figure 5. Fluidization maps for static bed height of $1 \mathrm{~m}$; (left) active section: L, (right) active section: S. 

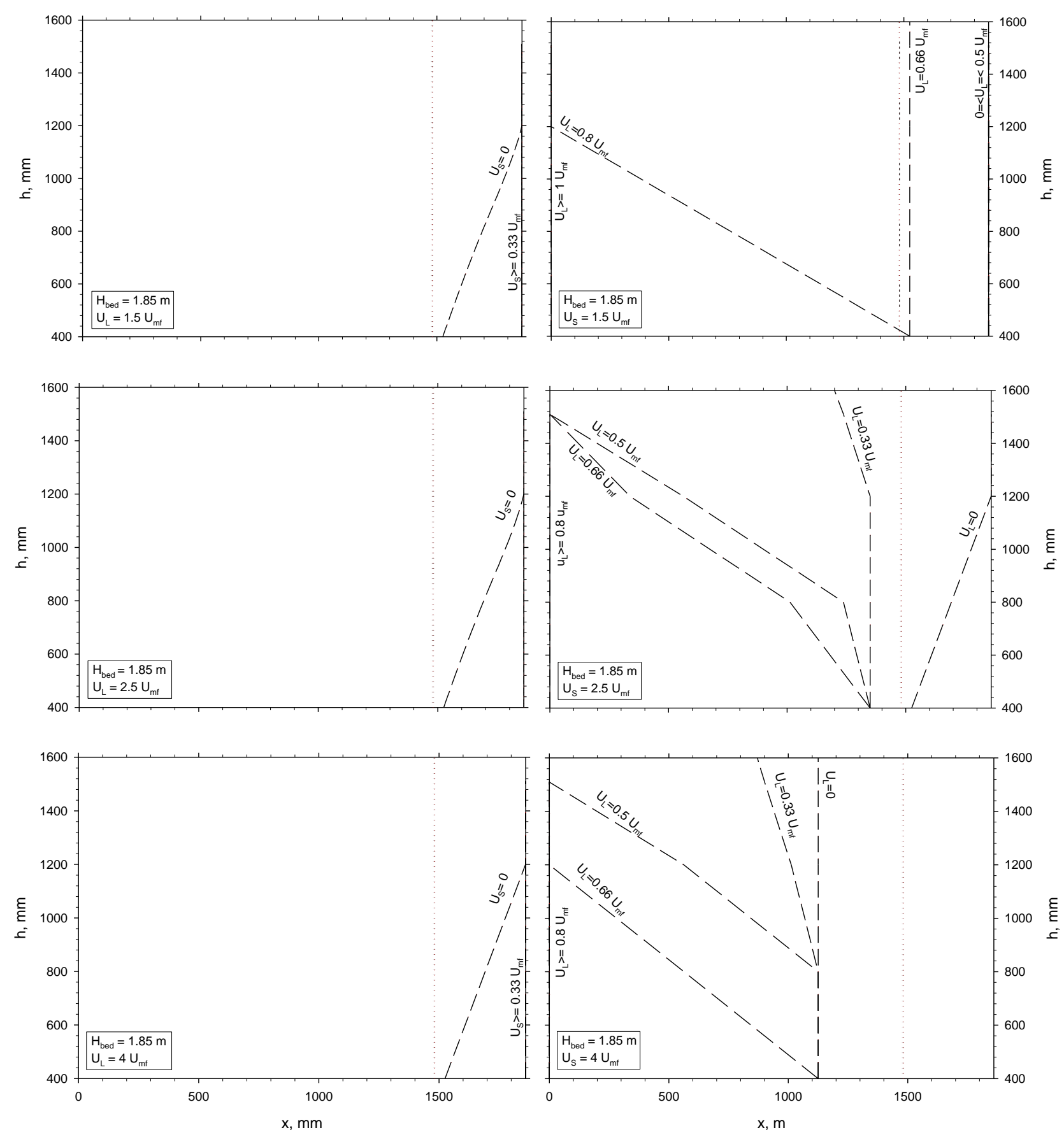

Figure 6. Fluidization maps for static bed height of $1.85 \mathrm{~m}$; (left) active section: L, (right) active section: $\mathrm{S}$.

The influence of the static bed height on bed compartmentation is better highlighted in Figure 7 , which refers only to experiments in which $S$ was the active section. It is evident that the boundary between the fluidized and non-fluidized regions reported for different static bed height does not significantly change for $U_{S}=2.5$ and $4 U_{m f}$, whereas it is influenced by the bed height for $U_{S}=1.5 U_{m f}$. Under the latter operating condition, increasing static bed height can bring about de-fluidization of the whole bed, including the active $S$ section of the bed. 

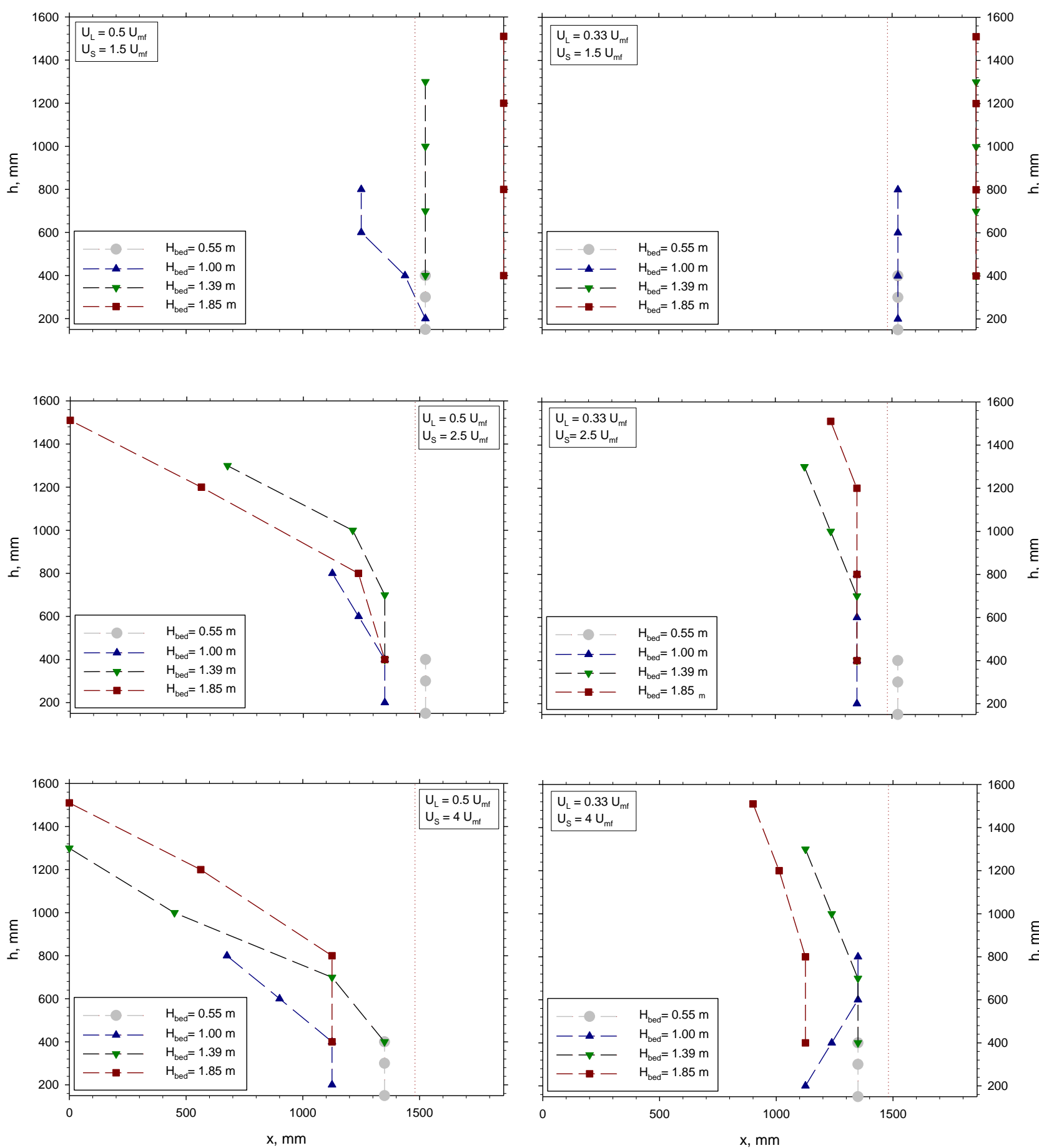

Figure 7. Fluidization maps for different values of the static bed height. (a) $U_{L}=0.5 U_{m f}, U_{S}=1.5,2.5$, $4 U_{m f}$ and (b) $U_{L}=0.33 U_{m f}, U_{S}=1.5,2.5,4 U_{m f}$.

Altogether, analysis of fluidization maps indicates that a perfectly compartmented fluidized bed is not trivially obtained by using a compartmented windbox. Extensive crossflow is established between the "active" and "passive" regions of the bed, so that undesired fluidization of the passive compartment or, alternatively, defluidization of the active compartment of the bed may onset, both hampering effective compartmented fluidization. Experimental results like those reported in Figures 4-7 provide the basis for controlling compartmented fluidization by proper partitioning of fluidizing gas between the active and passive sections of the bed. 


\subsection{Dynamic characterization of bubble and dense phases under uneven fluidization conditions}

Bed hydrodynamics under uneven fluidization conditions has been further investigated by scrutinizing the dynamic features of bubble and dense phase by analysis of local volume fraction of bed solids obtained from electrical capacitance signals.

The general features of time-resolved void fraction profiles corresponding to even bubbling conditions, to uneven fluidization conditions and to packed bed conditions are highlighted in Figure 8, corresponding to a static bed height of $1 \mathrm{~m}$. The Figure clearly highlights: a) the well established bubbly flow superimposed over the dynamical patterns of the emulsion phase (figure 8A); b) the mobility of the emulsion phase under uneven fluidization conditions, inferred from fluctuations of the void fraction (figure 8B); c) the absence of any significant dynamical pattern (other than noise) under de-fluidized conditions (figure $8 \mathrm{C}$ ). Deconvolution of the time-resolved void fraction profile into a bubble phase and a dense phase components enabled the computation of variables relevant to each phase, namely mean bubble frequency $(k)$, mean bubble rise velocity $\left(\mathrm{V}_{\mathrm{br}}\right)$, mean pierced length $\left(\mathrm{l}_{\mathrm{b}}\right)$ and mean local bubble fraction $\left(\varepsilon_{b}\right)$ in the bubble phase, standard deviation of voidage fluctuations ( $\left.\sigma_{\text {dense }}\right)$ and local solid dispersion coefficient $(D)$ in the dense phase. The dynamic features of the dense phase have been further analyzed by computing Power Spectral Density (PSD) functions with the aim of identifying dominant frequencies, which are related to the mobility of dense phase and, in turn, to the local solid dispersion coefficient. Figure 9 reports PSD of the time series of bed solids volume fraction of dense phase measured under even and uneven fluidization conditions for specific locations inside the bed. The dominant frequency under even fluidization conditions is typically about $2 \mathrm{~Hz}$, whatever the fluidization velocity. This result is consistent with coherent motion of the emulsion phase associated with the "natural frequency" of fluidized bed (piston-like bed oscillations). Instead, under uneven fluidization conditions, the power at the dominant frequency decreases until it vanishes as the bed becomes defluidized, while the dominant frequency is shifted toward $4 \mathrm{~Hz}$. 

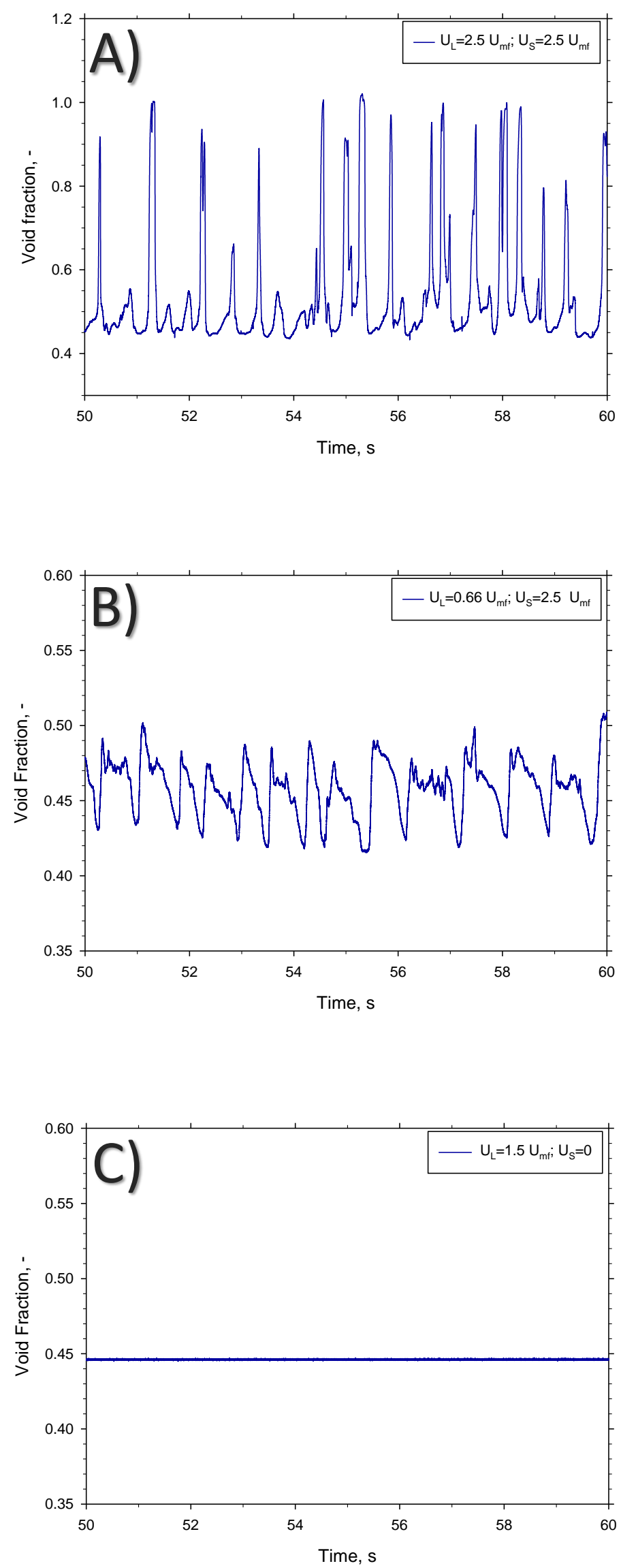

Figure 8. Time-resolved void fraction profiles for static bed height $1 \mathrm{~m}$. A) evenly fluidized bed, $x=1697 \mathrm{~mm}$; B) unevenly fluidized bed, $x=1506 \mathrm{~mm}$; C) fixed bed, $x=1506 \mathrm{~mm}$. 

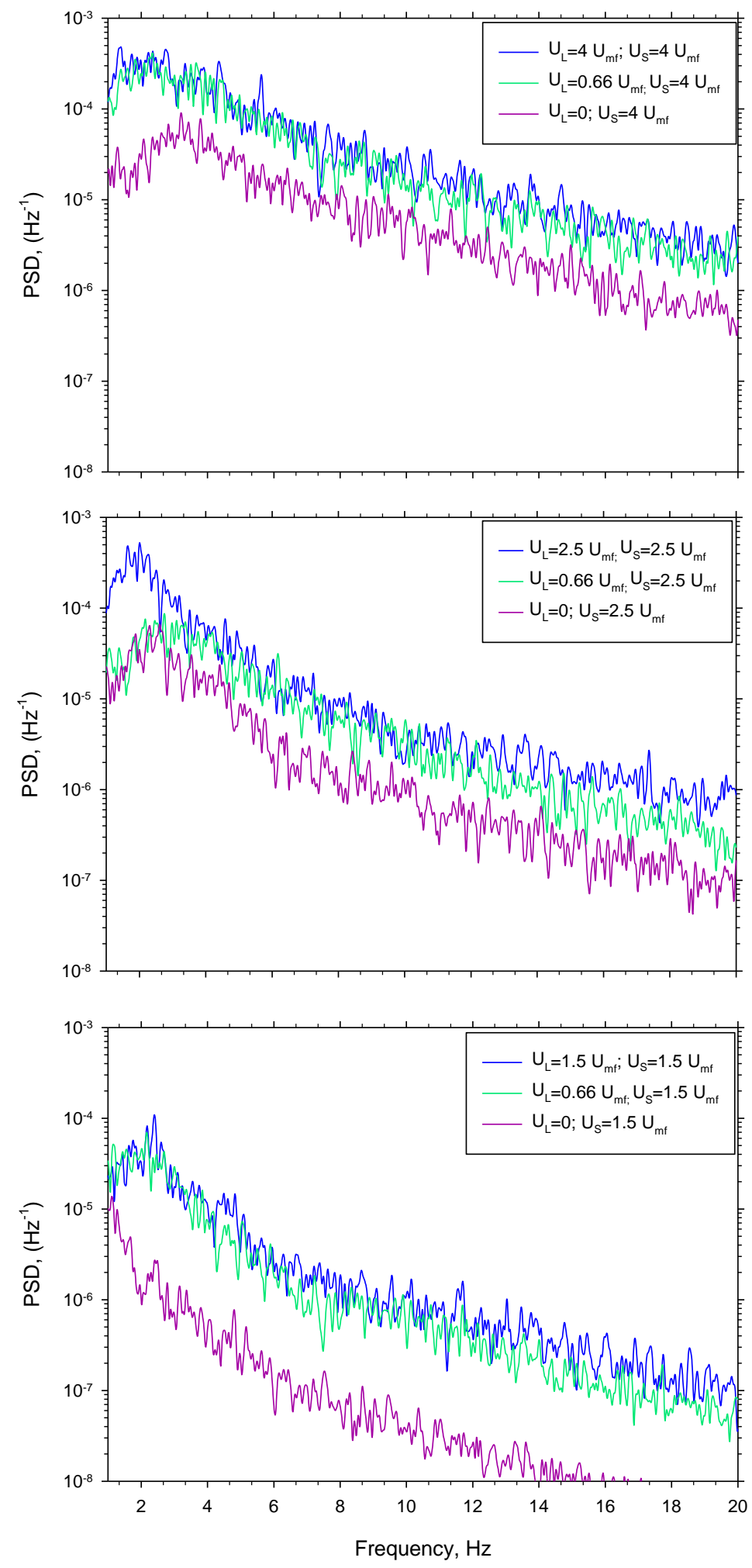

Figure 9. Power spectrum density (PSD) functions of dense phase volume fraction for $x=1506 \mathrm{~mm}$, $H_{\text {bed }}=0.55 \mathrm{~m}$ and for different operating conditions.

Figures 10,11 and 12 report the properties of the bubble phase, i.e. the mean bubble frequency $k$, the mean bubble rise velocity $v_{b r}$ and the mean bubble pierced length $I_{b}$, respectively, for different operating conditions. Reported data refer to measurements performed at two different axial positions $(400$ and $800 \mathrm{~mm})$ and at four lateral positions around the virtual bed separation between $\mathrm{S}$ and $\mathrm{L}$ 
compartments. Data refer to a static bed height of $1 \mathrm{~m}$. Two cases have been scrutinized: moderately uneven fluidization, corresponding to the minimum fluidizing gas velocity necessary to fluidize the whole bed; strongly uneven fluidization, corresponding to setting to 0 the gas superficial velocity in the passive zone. Figures report data points measured under uneven fluidization conditions at different locations in the bed, compared with average values recorded when the bed was fluidized evenly (at $U_{S}=U_{L}=1.5,2.5$ and $4 U_{m f}$ ) and reported in the figures as dashed lines. The virtual bed separation between compartments $S$ and $L$ is also reported in the figures as a vertical dotted line.

Analysis of Figures 10,11 and 12 confirms that effective bed compartmentation is reflected by the properties of the bubble phase as the active compartment (either $S$ or $L$ ) is operated at 2.5 and 4 $U_{m f}$. However, the hydrodynamic features of the bubble phase change when they are measured close to the virtual bed separation between the compartments: $k, \mathrm{v}_{\mathrm{br}}$ and $\mathrm{l}_{\mathrm{b}}$ all decrease with $\mathrm{x}$ when $L$ is the active section, whereas they increase with $x$ when $S$ is the active compartment. The change of bubble phase properties along $\mathrm{x}$ is more pronounced at the upper measurement position $(\mathrm{h}=800$ $\mathrm{mm}$ ). It is inferred that gas cross flow between the active and passive compartments increases along the bed height and equalizes the properties of the two compartments at given $\mathrm{h}$. For a fluidization velocity equal to $1.5 U_{m f}$, regardless of whether $S$ is the active or passive compartment, a bubble phase can hardly be detected from electrical capacitance measurements. 

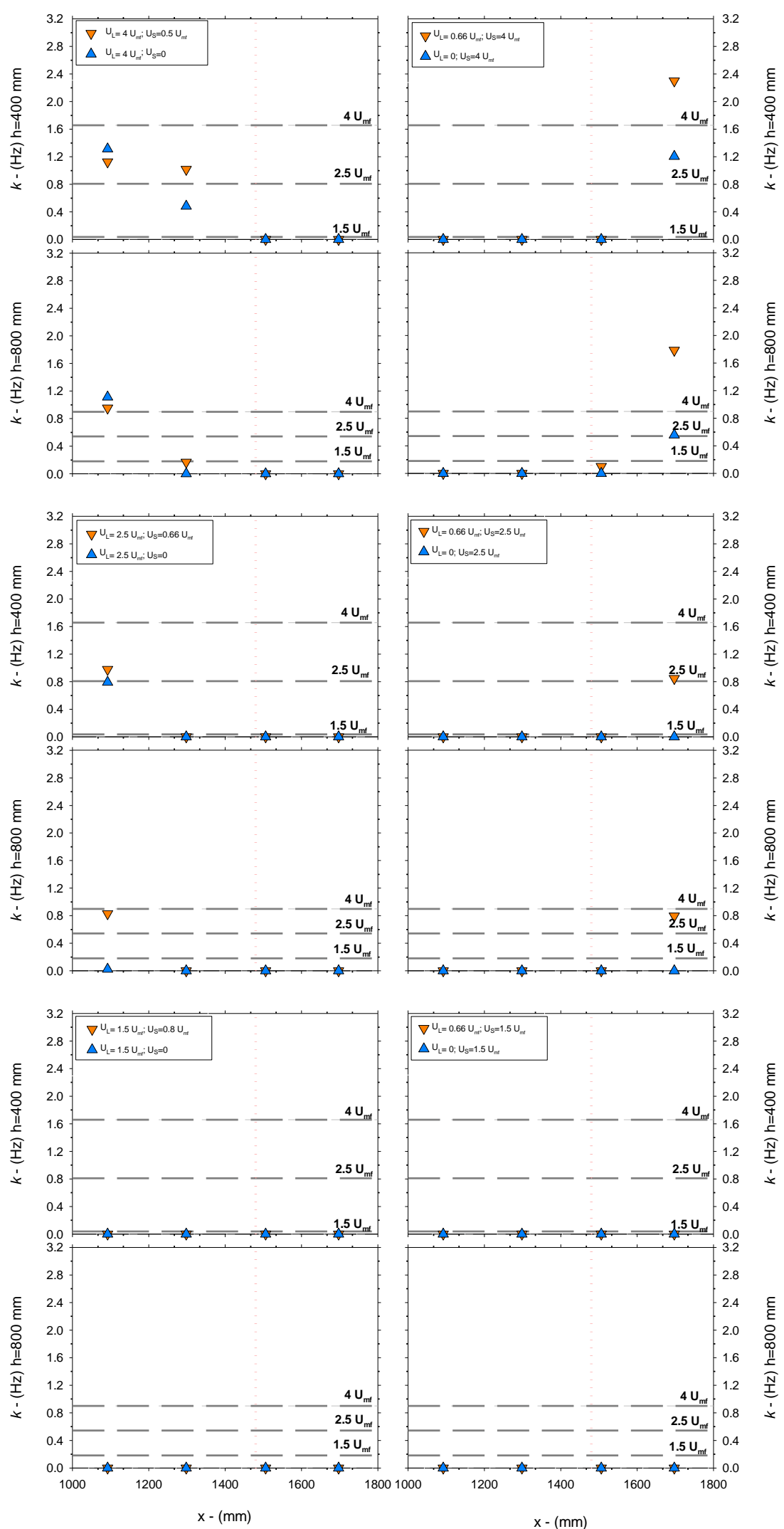

Figure 10. Mean bubble frequency as a function of $x$ at $h=400 \mathrm{~mm}$ and $\mathrm{h}=800 \mathrm{~mm}$ and static bed height of $1 \mathrm{~m}$ for different partitioning of fluidizing gas. Vertical dotted line: virtual bed separation line between $L$ and $S$ compartment. Horizontal dashed lines: average values recorded under even fluidization conditions. 

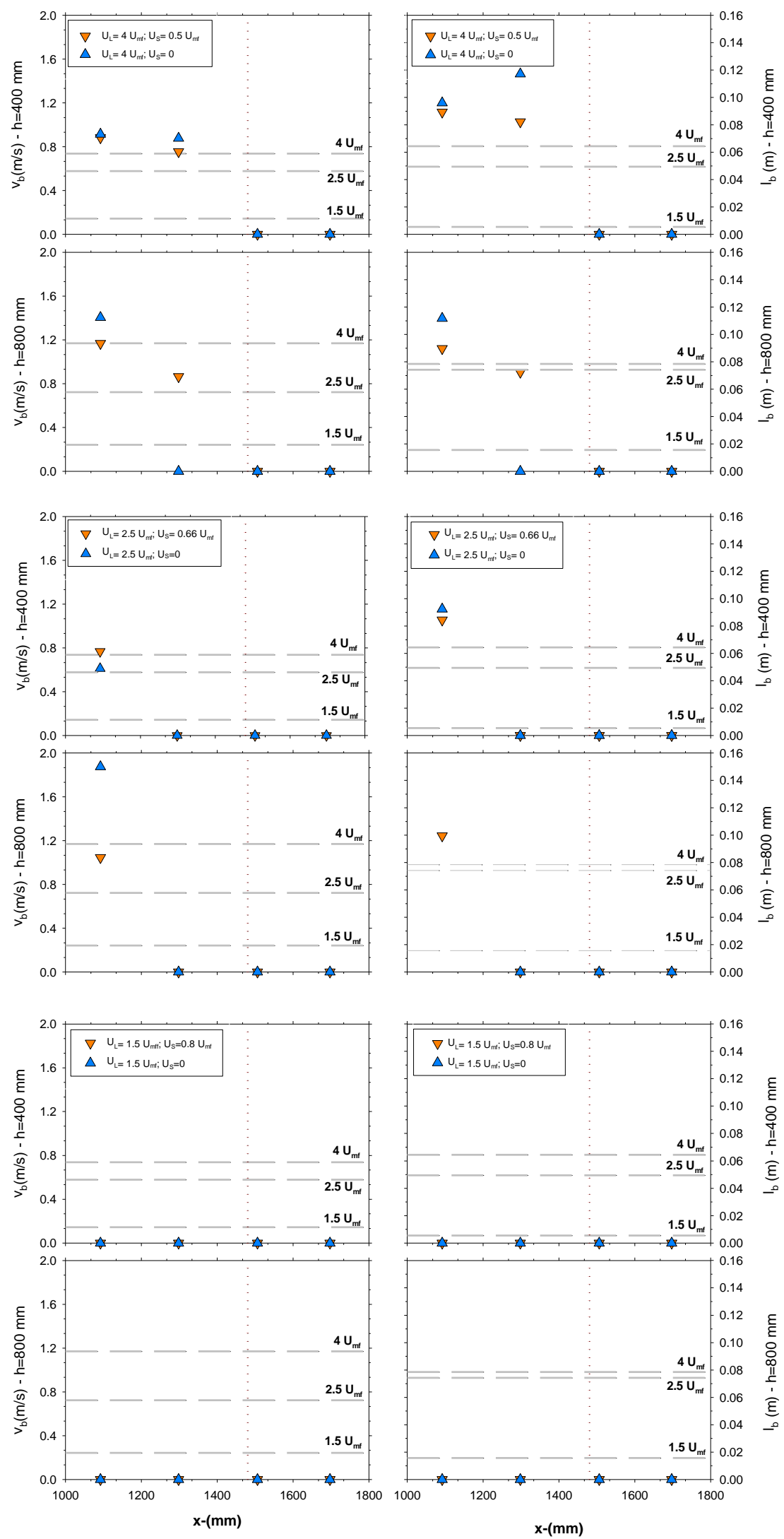

Figure 11. Mean bubble rise velocity and mean bubble pierced length as a function of $x$ at $h=400$ $\mathrm{mm}$ and $\mathrm{h}=800 \mathrm{~mm}$. Static bed height: $1 \mathrm{~m}$. Active section: L. Vertical dotted line: virtual bed separation line between $L$ and $S$ compartment. Horizontal dashed lines: average values recorded under even fluidization conditions. 

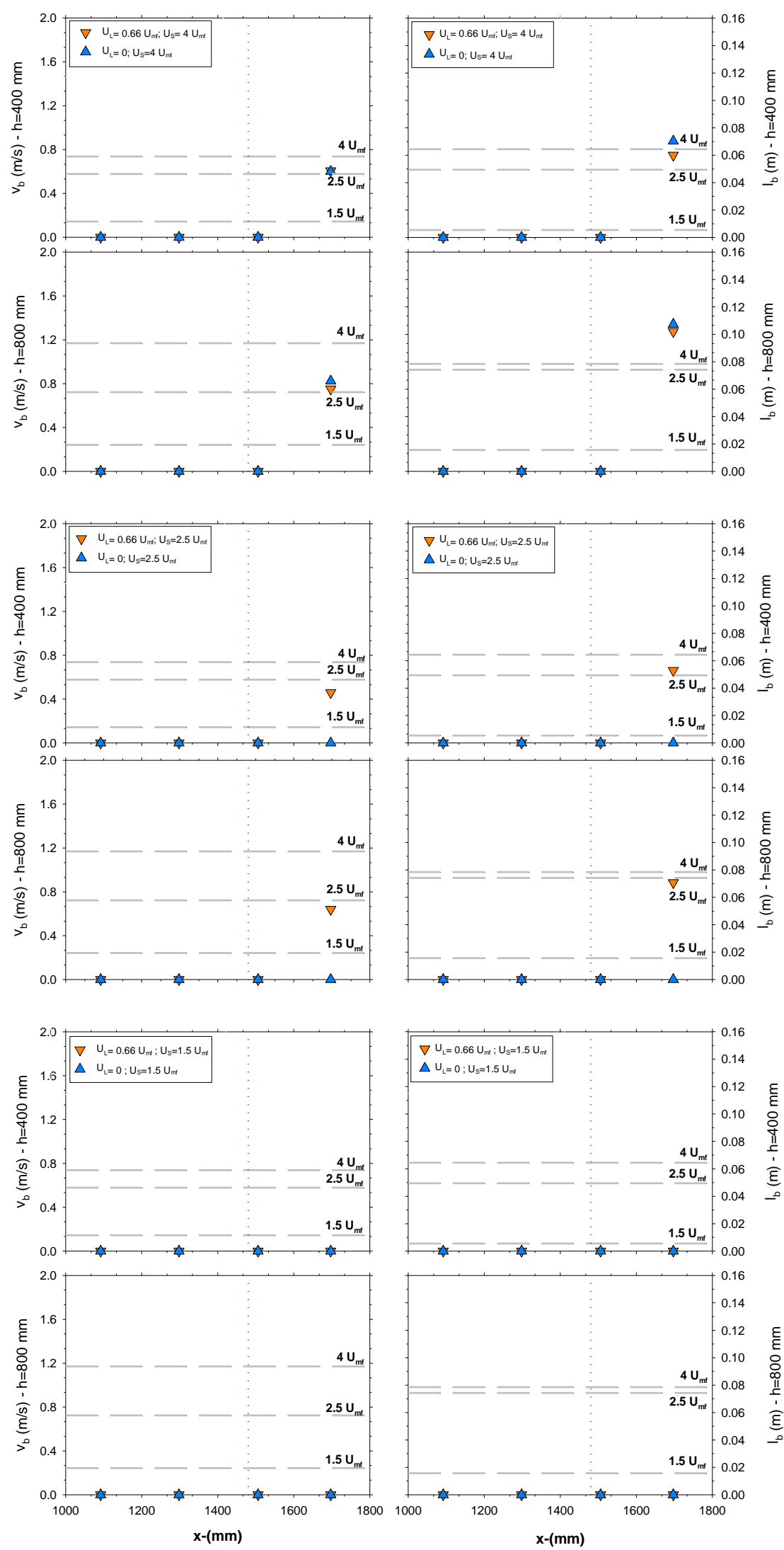

Figure 12. Mean bubble rise velocity and mean bubble pierced length as a function of $x$ at $h=400$ $\mathrm{mm}$ and $\mathrm{h}=800 \mathrm{~mm}$. Static bed height: $1 \mathrm{~m}$. Active section: $\mathrm{S}$. Vertical dotted line: virtual bed separation line between $L$ and $S$ compartment. Horizontal dashed lines: average values recorded under even fluidization conditions. 
Experimental results obtained with a static bed height of $0.55 \mathrm{~m}$ at axial measurement position of $400 \mathrm{~mm}$ with and static bed height of $1 \mathrm{~m}$ are very similar and are not reported.

The dynamics of the dense phase has been characterized by estimating the standard deviation of voidage in the dense phase ( $\left.\sigma_{\text {dense }}\right)$ and the local dispersion coefficient $(D)$ of the solids. These variables are reported in Figures 13 and 14, for the same operating conditions considered for the bubble phase. Results in Figures 13 and 14 reinforce conclusions already drawn from analysis of the bubble phase. As the fluidization velocity in either compartment is set at $1.5 U_{m f}$, the mobility of the dense phase is negligible throughout the bed. Increasing the fluidization velocity in one of the two compartment, the trend of $\sigma_{\text {dense }}$ vs $x$ closely mirrors those observed for the properties of the bubble phase: it increases with $\mathrm{x}$ when the $\mathrm{S}$ compartment is active, and decreases when the $\mathrm{L}$ compartment is active. The same trend is observed for the local solid dispersion coefficient $D$ at $h=400 \mathrm{~mm}$, whereas $D$ is fairly constant with $x$ at $h=800 \mathrm{~mm}$.

A very interesting feature stems out when the mobility of the dense phase, expressed by $D$, is spatially correlated with the parameters of the bubble phase. Indeed, fairly large values of $D$, hence vigorous particle motion, are observed even at locations where bubbly flow is not observed. This feature is observed also in strongly uneven fluidization conditions and is emphasized in the upper part of the fluidized bed. It is inferred that enhanced solids mobility at locations where bubbles are not detected arises due to the establishment of coherent bed solids circulation of large correlation length promoted by uneven fluidization [30-33]. 

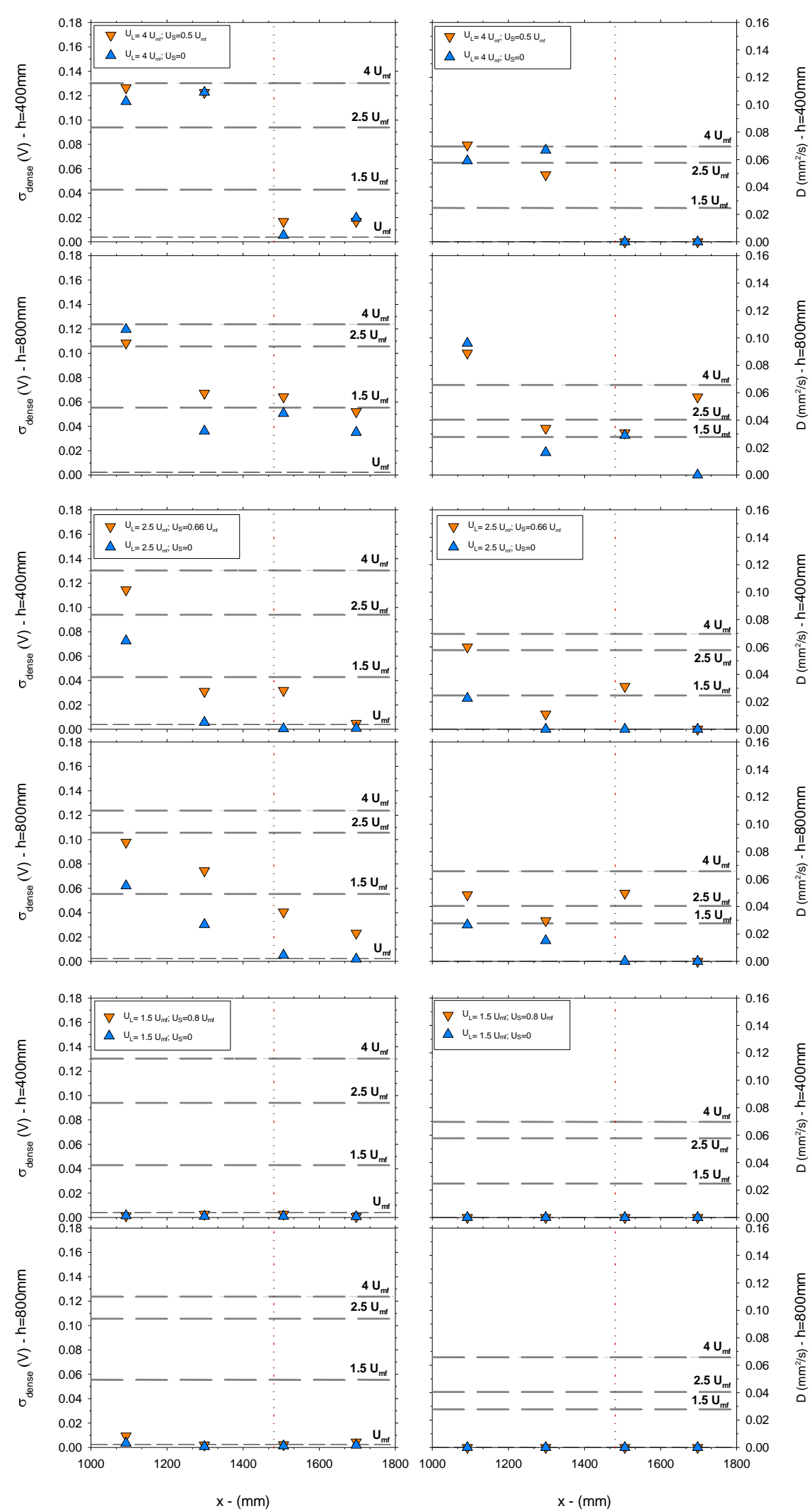

Figure 13. Dense phase standard deviation and local dispersion coefficient as a function of $x$ at $\mathrm{h}=400 \mathrm{~mm}$ and $\mathrm{h}=800 \mathrm{~mm}$. Static bed height: $1 \mathrm{~m}$. Active section: L. Vertical dotted line: virtual bed separation line between $L$ and $S$ compartment. Horizontal dashed lines: average values recorded under even fluidization conditions. 

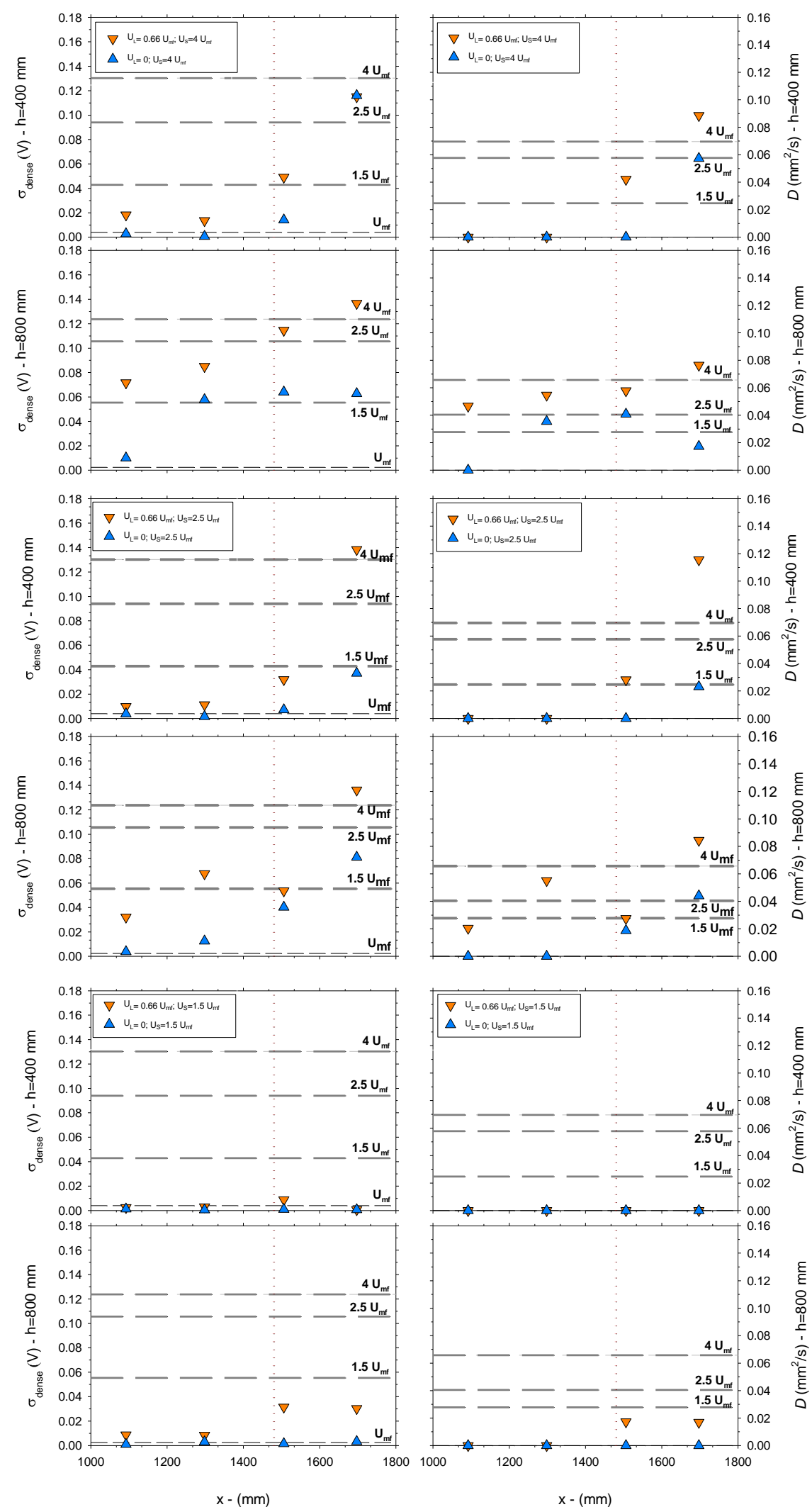

Figure 14. Dense phase standard deviation and local dispersion coefficient as a function of $x$ at $\mathrm{h}=400 \mathrm{~mm}$ and $\mathrm{h}=800 \mathrm{~mm}$. Static bed height: $1 \mathrm{~m}$. Active section: $\mathrm{S}$. Vertical dotted line: virtual bed separation line between $L$ and $S$ compartment. Horizontal dashed lines: average values recorded under even fluidization conditions. 


\section{Conclusions}

The hydrodynamics of a near-2D dense gas-fluidized bed operated at ambient conditions and equipped with a compartmented distributor of fluidizing gas, consisting of two spargers, has been characterized. The main goal was that of establishing whether compartmented fluidization of the bed could be accomplished by uneven feeding of the fluidizing gas only, without physical separations or internals inside the bed. Uneven fluidization was accomplished by partitioning of the fluidizing gas between the sections of the distributor: a larger gas superficial velocity (exceeding the incipient fluidization velocity) was established in the "active" section of the distributor, a smaller (or even 0) gas superficial velocity was established in the passive section of the distributor.

Space- and time-resolved pressure maps inside the bed were worked out to generate fluidization maps, reporting the regions in the bed that are in the fluidized and in the de-fluidized state, as the gas feed rate to either sparger was varied. Moreover, dynamical patterns of the bubble and of the emulsion phases have been scrutinized by analysis of space- and time-resolved void fraction profiles obtained from electrical capacitance signals.

Results confirm the expected inherent tendency of the bed to equalize uneven fluidization. Crossflow of fluidizing gas from the active to the passive sections of the bed, driven by lateral pressure gradients, promotes fluidization of the passive section and/or defluidization of the active section of the bed. Crossflow becomes increasingly important as the bed depth increases and this makes compartmented fluidization of deep beds more problematic.

Fluidization maps provide the basis for the design and operation of gas distributors to effectively achieve compartmented fluidization of the fluidized bed. Analysis of space- and time-resolved local bed voidage profiles gives useful insight on the establishment of gross bed solids circulation patterns: large scale coherent solids mobility is promoted also in the passive section of the bed by particle gulf streaming induced by bubbly flow in the active section.

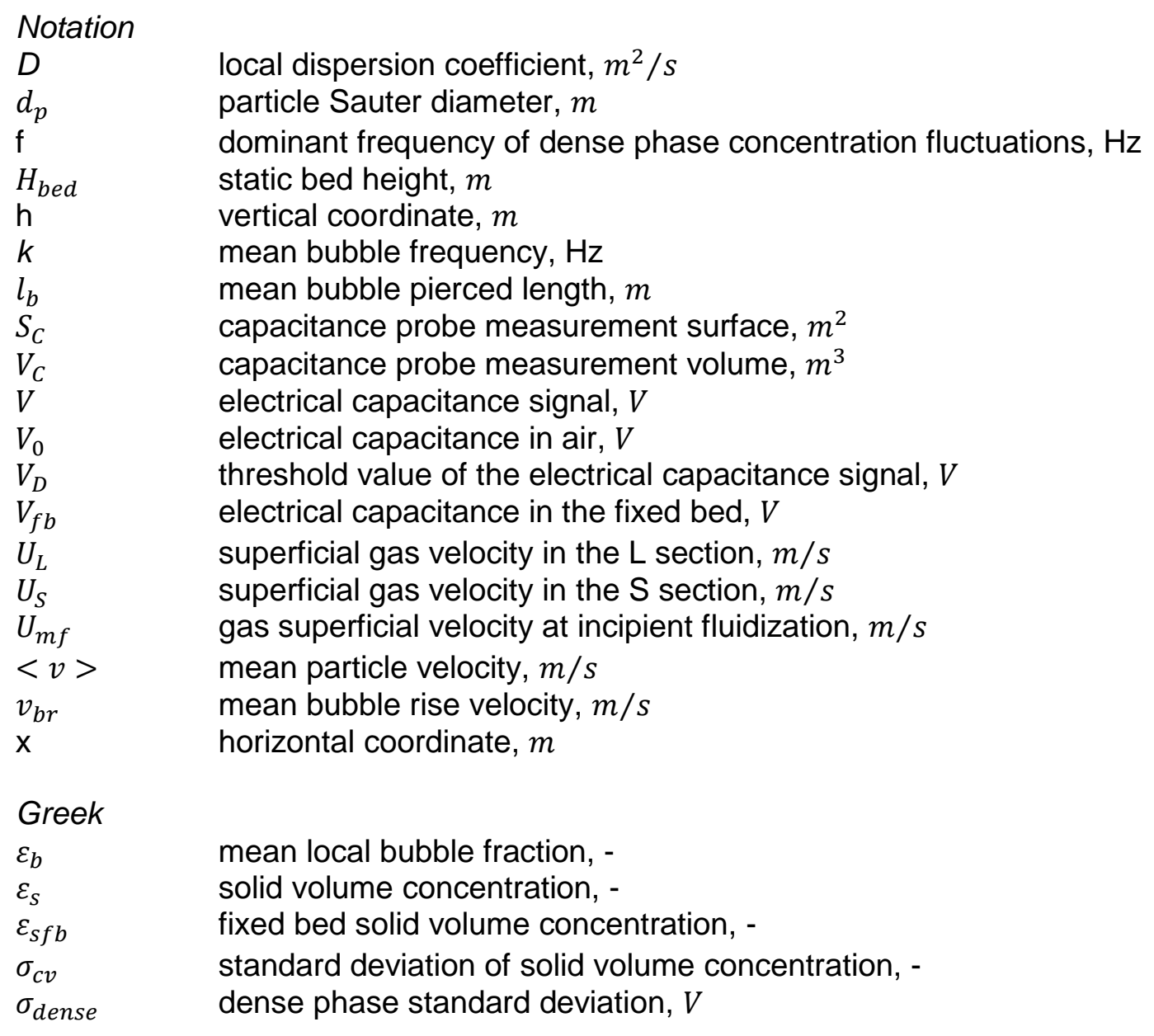




\section{Acknowledgments}

The study is part of the project "PON01_00761: Solare Termodinamico con Accumulo Solido (SOLTESS)" funded by MIUR in the framework of the Program PON Ricerca e Competitività 20072013. The support of Mr Antonio Cammarota, Mr Gianfranco Vanacore and Mr Gennaro Somma is gratefully acknowledged. 


\section{References}

[1] C. K. Ho, B. D. Iverson, Review of high-temperature central receiver designs for concentrating solar power, Renew Sust Energ Rev 29 (2014) 835-846.

[2] H. Zhang, J. Baeyens, G. Cáceres, J. Degrève, Y. Lv, Thermal energy storage: Recent developments and practical aspects, Prog Energ Combust 53 (2016) 1-40.

[3] H. Benoit, L. Spreafico, D. Gauthier, G. Flamant, Review of heat transfer fluids in tubereceivers used in concentrating solar thermal systems: Properties and heat transfer coefficients, Renew Sust Energ Rev 55 (2016) 298-315.

[4] H. Zhang, H. Benoit, D. Gauthier, J. Degrève, J. Baeyens, I. Pérez López, M. Hemati, G. Flamant, Particle circulation loops in solar energy capture and storage: Gas-solid flow and heat transfer considerations, Appl Energ 161 (2016) 206-224.

[5] G. Flamant, D. Gauthier, H. Benoit, J.-L. Sans, R. Garcia, B. Boissière, R. Ansart, M. Hemati, Dense suspension of solid particles as a new heat transfer fluid for concentrated solar thermal plants: On-sun proof of concept, Chem Eng Sci 102 (2013) 567-576.

[6] H. Benoit, I. Pérez López, D. Gauthier, J.-L. Sans, G. Flamant, On-sun demonstration of a $750{ }^{\circ} \mathrm{C}$ heat transfer fluid for concentrating solar systems: Dense particle suspension in tube, Sol Energy 118 (2015) 622-633.

[7] R. Chirone, P. Salatino, P. Ammendola, R. Solimene, M. Magaldi, R. Sorrenti, G. De Michele, F. Donatini, Development of a novel concept of solar receiver/thermal energy storage system based on compartmented dense gas fluidized beds. In: Proc. 14th Int. Conf. on Fluidization - From Fundamentals To Products, Noordwijkerhout, The Netherlands, (2013) pp. 95-102.

[8] P. Salatino, P. Ammendola, P. Bareschino, R. Chirone, R. Solimene, Improving the thermal performance of fluidized beds for concentrated solar power and thermal energy storage, Powder Technol 290 (2016) 97-101.

[9] F. Berruti, D. S. Scott, E. Rhodes, Measuring and Modelling Lateral Solid Mixing in a 3Dimensional batch Gas-Solid Fluidized Bed Reactor, Can J Chem Eng 64 (1986) 48-56.

[10] F. Niklasson, H. Thunman, F. Johnsson, B. Leckner, Estimation of Solids Mixing in a Fluidized-Bed Combustor, Ind Eng Chem Res 41 (2002) 4663-4673.

[11] E. Sette, D. Pallarès, F. Johnsson, Experimental evaluation of lateral mixing of bulk solids in a fluid-dynamically down-scaled bubbling fluidized bed, Powder Technol 263 (2014) 74-80.

[12] G. Flamant, Theoretical and experimental study of radiant heat transfer in a solar fluidizedbed receiver, AIChE J 28 (1982) 529-535.

[13] D.M. Bachovchin, D.H. Archer, D.H. Neale, Heat transfer in a fluidized-bed solar thermal receiver, AIChE Symp Ser 79 (1983) 27-36.

[14] E. Alonso, M. Romero, Review of experimental investigation on directly irradiated particles solar reactors, Renew Sust Energ Rev 41 (2015) 53-67.

[15] C. Tregambi, R. Chirone, F. Montagnaro, P. Salatino, R. Solimene, Heat transfer in directly irradiated fluidized beds, Sol Energy 129 (2016) 85-100.

[16] G. Angrisani, K. Bizon, R. Chirone, G. Continillo, G. Fusco, S. Lombardi, F.S. Marra, F. Miccio, C. Roselli, M. Sasso, R. Solimene, F. Tariello, M. Urciuolo, Development of a new concept solar-biomass cogeneration system, Energ Convers Manage 75 (2013) 552-560.

[17] C. Tregambi, F. Montagnaro, P. Salatino, R. Solimene, R., A model of integrated calcium looping for $\mathrm{CO}_{2}$ capture and concentrated solar power, Sol Energy 120 (2015) 208-220.

[18] A. Steinfeld, V. Kirillov, G. Kuvshinov, Y. Mogilnykh, A. Reller, Production of filamentous carbon and hydrogen by solarthermal catalytic cracking of methane, Chem Eng Sci 52 (1997) 35593603.

[19] P. von Zedtwitz, A. Steinfeld, Steam-gasification of coal in a fluidized-bed/packed-bed reactor exposed to concentrated thermal radiation - Modeling and experimental validation, Ind Eng Chem Res 44 (2005) 3852-3861.

[20] P. von Zedtwitz, W. Lipiński, A. Steinfeld, Numerical and experimental study of gas-particle radiative heat exchange in a fluidized-bed reactor for steam-gasification of coal, Chem Eng Sci 62 (2007) 599-607.

[21] N. Gokon, S. Takahashi, H. Yamamoto, T. Kodama, Thermochemical two-step water-splitting reactor with internally circulating fluidized bed for thermal reduction of ferrite particles, Int J Hydrogen Energ 33 (2008) 2189-2199. 
[22] N. Gokon, T. Mataga, N. Kondo, T. Kodama, Thermochemical two-step water splitting by internally circulating fluidized bed of $\mathrm{NiFe}_{2} \mathrm{O}_{4}$ particles: Successive reaction of thermal-reduction and water-decomposition steps, Int J Hydrogen Energ 36 (2011) 4757-4767.

[23] N. Gokon, T. Izawa, T. Kodama, Steam gasification of coal cokes by internally circulating fluidized-bed reactor by concentrated Xe-light radiation for solar syngas production, Energy 79 (2015) 264-272.

[24] C.Y. Wen, Y.H. Yu, A generalized method for predicting the minimum fluidization velocity, AIChE J 12 (1966) 610-612.

[25] B. Hage, J. Werther, The guarded capacitance probe - a tool for the measurement of solids flow patterns in laboratory and industrial fluidized bed combustors, Powder Technol 93 (1997) 235245.

[26] J. Werther, O. Molerus, The local structure of gas fluidized beds - I. A statistically based measuring system, Int J Multiphas Flow 1 (1973) 103-122.

[27] J.T. Jenkins, S.B. Savage, A theory for the rapid flow of identical, smooth, nearly elastic spherical particles, J. Fluid Mech. 130 (1983) 187-202.

[28] D. Gidaspow, Multiphase flow and fluidization: continuum and kinetic theory descriptions, Academic Press, San Diego, 1994.

[29] J. Sánchez-Prieto, A. Soria-Verdugo, J. Gómez-Hernández, J.V. Briongos, D. Santana, Maldistribution detection in bubbling fluidized beds, Chem. Eng. J. 270 (2015) 272-281.

[30] A.K. Patel, S.S. Waje, B.N. Thorat, A.S. Mujumdar, Tomographic diagnosis of gas maldistribution in gas-fluidized beds, Powder Technol. 185 (2008) 239-250.

[31] J. M. D. Merry, J. F. Davidson, Gulf-stream circulation in shallow fluidized beds, Trans. Inst Chem. Engs., 51 (1973), 361-368.

[32] G. Aprea, A. Cammarota, R. Chirone, R. Solimene, P. Salatino, Hydrodynamic characterization of the biomass combustion in a pilot scale fluidized bed combustor, Chem. Eng. Trans. 32 (2013) $1519-1524$.

[33] H. R. Norouzi, N. Mostoufi, Z. Mansourpour, R. Sotudeh-Gharebagh, J. Chaouki, Characterization of solids mixing patterns in bubbling fluidized beds, Chem Eng Res Des 89 (2011) 817-826. 